\title{
Nanomedicine Awareness among Medical Students in Saudi Arabia
}

\author{
Hamad Albraidi ${ }^{1}$ and Mohammed Al-Haddab ${ }^{2, *}$ \\ ${ }^{1}$ College of Medicine, King Saud University, Riyadh, Saudi Arabia \\ ${ }^{2}$ Department of Dermatology, King Saud University, Riyadh, Saudi Arabia
}

Received: 23 October 2017; accepted: 23 March 2018

\begin{abstract}
Objectives: The study's aim was to assess the medical students' knowledge and understanding of concepts related to basic nanotechnology and its applications in nanomedicine among medical students at King Saud University. Methods: An observational cross-sectional study was carried out by using an online questionnaire that was sent to all the medical students studying at King Saud University during the summer of 2016 July-August. The sample size of the study was 162 medical students. The questionnaire consisted of 11 items, including both fixed and free answer-type questions. The questionnaire was sent to 1413 medical students, with a response percentage of $8.72 \%$. Results: Students' perception of the basic nanotechnology was assessed, $63.0 \%(n=102)$ of the students identified the correct definition of nanoparticle size. Unfortunately, only $40.7 \%(n=66)$ of the students heard about nanomedicine. Most of the information sources where from university $25.3 \%, 24.1 \%$ from internet, and $11 \%$ from television. $81.8 \%$ of our medical students, had little knowledge about the risk-benefits of nanomedicine. Interestingly, about $72.8 \%(n=118)$ of the students think that nanotechnology is not effectively used in the medical field. Conclusion: Medical students at king Saud university, showed that they have inadequate knowledge about nanotechnology and its applications in nanomedicine. Nanomedicine education should be implemented in the curriculum of the medical colleges in Saudi Arabia, to improve the awareness and future involvement in nanomedicine.
\end{abstract}

Keywords: nanomedicine, medical students, nanotechnology awareness, medical education, Saudi Arabia

\section{Introduction}

Nanotechnology is a term that involve a spectrum of technologies, techniques and processes that can deal with a matter at the nanoscale - fall in between 1 nanometer to 100 nanometers in size. Many products have been developed with nanotechnology applications, including technological devices, pharmaceutical products, building materials and in the field of medicine.

In medicine, nanoparticles toxicity remains an obstacle in the development of nanomedicine, as there is insufficient tests or measurements to determine and identify the toxicity of a substance. For instance, Silver is not harmful in its bulk form, but it is an antibacterial in the nano-size form [1].

This is an open-access article distributed under the terms of the Creative Commons Attribution-NonCommercial 4.0 International License (https://creativecommons.org/licenses/by-nc/4.0/), which permits unrestricted use, distribution, and reproduction in any medium for non-commercial purposes, provided the original author and source are credited, a link to the CC License is provided, and changes - if any - are indicated.

* Corresponding author, Dermatology Department, College of Medicine, King Saud University, P.O. Box 7805 (82), Riyadh, 11472 Saudi Arabia. Tel: +966114691426, Email: malhaddab@gmail.com 
The European Science Foundation (ESF) defined nanomedicine as "the science and technology of diagnosing, treating, preventing disease and traumatic injury, of relieving pain, of preserving and improving human health, using molecular tools and molecular knowledge of the human body". [2].

There are several medical disciplines that its applications and interventions can be implemented like dermatology, ophthalmology, infectious diseases, urology and surgery. Most of the nanopharmaceutical products are using the drug targeted delivery system, there are several routs to administer the nanomedical drugs (e.g. injectable, oral, pulmonary, dermal and ocular). In reality, the number of clinical trials are increasing and there are many FDAApproved drugs to treat various diseases using this technology [3].

In this regard, the awareness of nanomedicine is important to elicit in the medical students, as of this we needed to assess and question the awareness of this promising technology in our medical student at King Saud University.

\section{Methods}

\section{Study Design and Setting}

Quantitative (observational) cross-sectional study design was carried out by using an online questionnaire that was sent to all the medical students emails studying at King Saud University during the summer of 2016 (July-August).

\section{Study Population}

Medical students studying at King Saud University in the academic year 2015-2016 was selected according to predetermined criteria to ensure their relevance to the study purpose and for obtaining optimum results. Inclusion criteria: Individuals aged 18 years and older, males and females, english speaking subjects, from first year to the fifth year ( 5 academic years). Exclusion Criteria: Students who are going from preparatory year to the first year of medical school and those who are going to the internship.

\section{Sample Size}

The questionnaire was sent to 1413 medical students ( 820 males, 593 female) with a response percentage of $8.72 \%$.

\section{Data collection methods}

A questionnaire from previous study was used [4]. The questionnaire is divided into three parts; 1) "students' responses on the nanoscale" this corresponds to 1 st-3rd questions, 2) "students' responses on the nanomedicine" this corresponds to 4th -7 th questions. 3) "students' responses on nanomedicine perception" 8th -10 th. Only students who answer by yes to the 4th question will answer the second part of the questionnaire. The 11th question is an open question, to elicit student's perception of a hypothetical nanomedical procedure. The data was collected by means of the questionnaire consisting of 11 items including both fixed and free answer-type questions to elicit the participants' basic knowledge and opinions about risks of nanotechnology (see appendix). The questionnaire contained a full explanation of the study purpose. All information which has been obtained from participants was managed with high level of confidentiality. Each 
participant informed that he or she is allowed to accept or refuse the chance to participate in the study.

\section{Statistical analysis}

Data were analyzed by using Statistical Package for Social Studies (SPSS 22; IBM Corp., New York, NY,USA). Categorical variables were expressed as percentages. Chi square test was used for categorical variables. A $p<0.05$ value was considered statistically significant.

\section{Results}

\section{Characteristics of the medical students studying at King Saud University}

The characteristics of the medical students studying at King Saud University is listed in Table 1 showing that $n=38,23.5 \%$ of the respondents were in their first year, fifth year students were the least respondents. The percentage of female respondents $(n=96,59.3 \%)$ is slightly higher than male medical student's response.

Table 1. Characteristics of the subjects

\begin{tabular}{lcc}
\hline & Frequency & $\%$ \\
\hline Year of study & 38 & \\
First year & 33 & 23.5 \\
Second year & 29 & 20.4 \\
Third year & 34 & 17.8 \\
Fourth year & 28 & 21.0 \\
Fifth year & & 17.3 \\
\hline Gender & 66 & \\
Male & 96 & 40.7 \\
Female & & 59.3 \\
\hline
\end{tabular}

Perception of basic nanotechnology and nanomedicine

Table 2 illustrates students' perception of the basic nanotechnology knowledge of the nanoparticle size, surprisingly $n=102,63.0 \%$ of the students choose the correct answer. The students asked, if they heard or knew what nanomedicine is, about $n=66,40.7 \%$ answered yes, this is unpredictable observation as we assumed that medical students should at least heard of nanomedicine. Then if the students answered by yes to the nanomedicine knowledge question, they will proceed to the next question, from where did they heard about it (Fig. 1),

Table 2. Students' responses in the nano section

\begin{tabular}{llc}
\hline Question (science concept) & Possible responses & $\begin{array}{c}\text { Percentage of students who } \\
\text { provided responses }(n=162)\end{array}$ \\
\hline The size of the nanoparticle is & $10^{-9}$ & 63.0 \\
Do you know what nanomedicine is? & Yes & 40.7 \\
Where did you hear about nanomedicine? & University & 25.3 \\
\hline
\end{tabular}




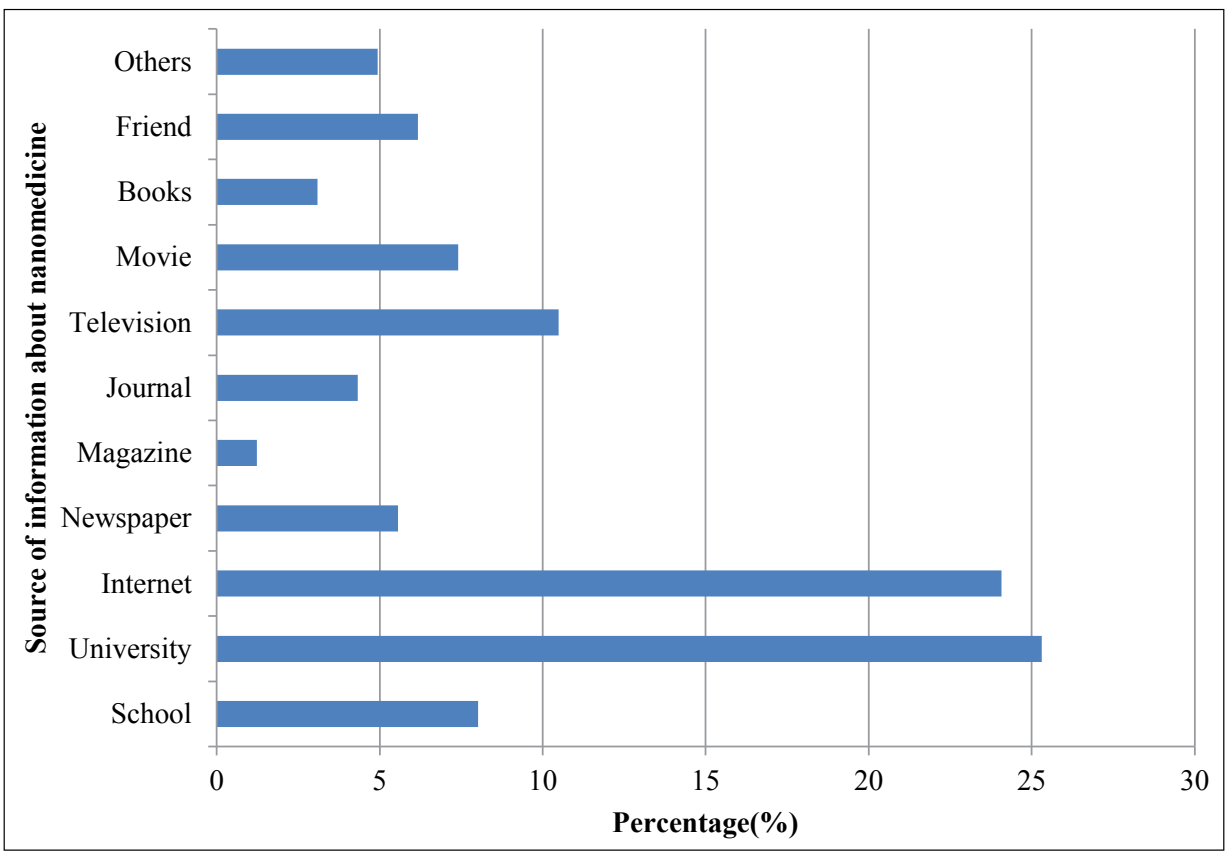

Fig. 1. Source of information about nanomedicine

most of the information sources, where from university $25.3 \%, 24.1 \%$ from internet, and $11 \%$ from television.

\section{Do you know what nanomedicine does in respect to ethics?}

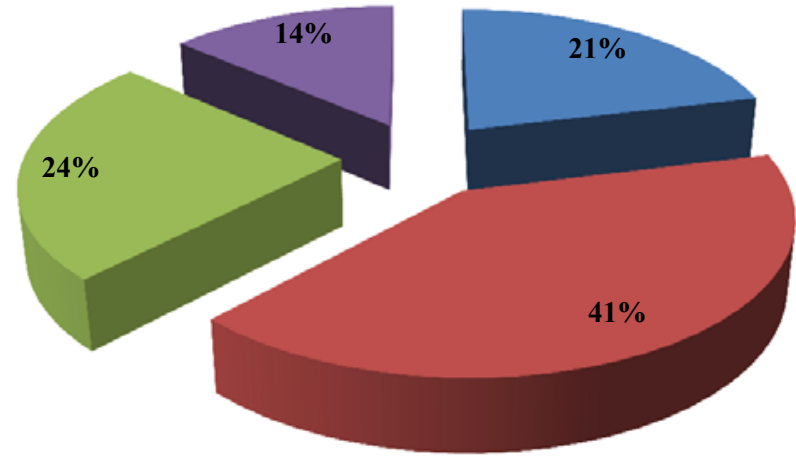

No ethical issues is excepted in the future

nisk assessment is needed in the clinical studies

Educating society members will reduce the ethical issues

- Public health and environment domain will be affected

Fig. 2. Medical students' knowledge about nanomedicine in respect to ethics 


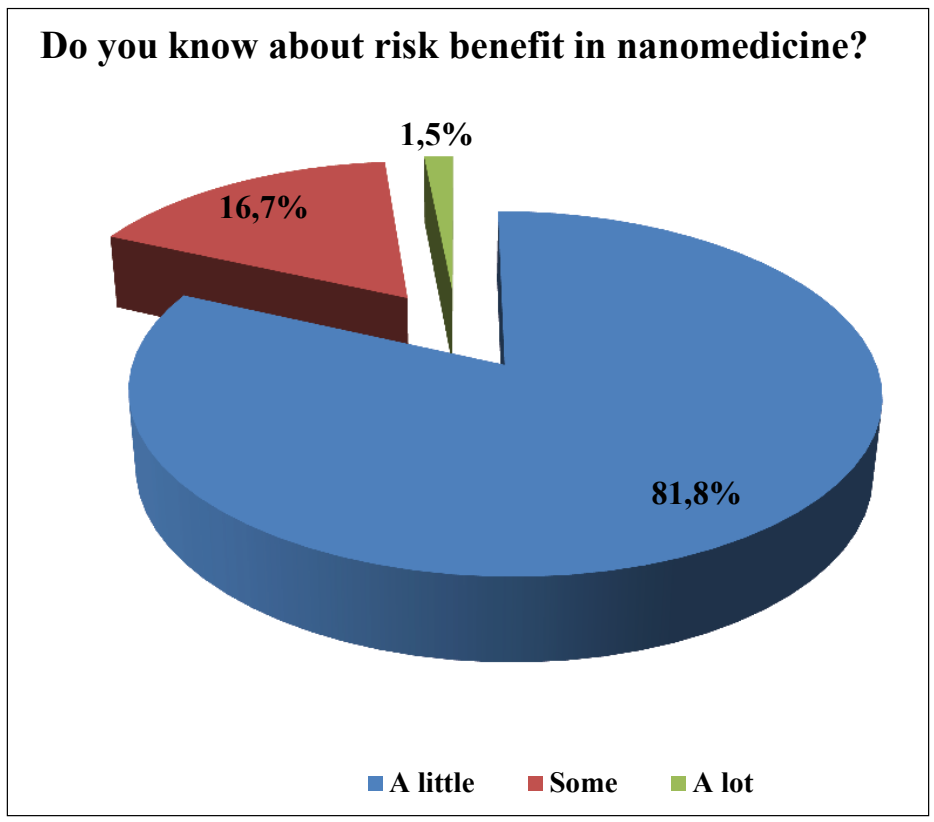

Fig. 3. Medical students' knowledge about risk benefit in nanomedicine

\section{Student's knowledge of nanomedicine risks}

Student's who recognize nanomedicine, were asked regarding the ethics (Fig. 2) and riskbenefits (Fig. 3) of nanomedicine. $41 \%$ were concerned more about risk assessment in clinical studies, $24 \%$ believed that education will help to reduce the ethical issues. When asked about the risks-benefits of nanomedicine, $81.8 \%$ had a little knowledge about it. This may

Table 3. Nanotechnology and nanomedicne application

\begin{tabular}{|c|c|c|c|c|c|c|c|}
\hline \multirow[t]{2}{*}{ Item } & \multicolumn{2}{|c|}{ All } & \multicolumn{2}{|c|}{ Male } & \multicolumn{2}{|c|}{ Female } & \multirow[t]{2}{*}{$p$ value } \\
\hline & Number & $\%$ & Number & $\%$ & Number & $\%$ & \\
\hline
\end{tabular}

Do you think public has awareness about application of nanotechnology used in the field of medicine?

\begin{tabular}{lrrrrrrr}
\hline Strongly agree & 3 & 1.9 & 2 & 3.0 & 1 & 1.0 & \\
Agree & 8 & 4.9 & 4 & 6.1 & 4 & 4.2 & \\
Undecided & 16 & 9.9 & 5 & 7.6 & 11 & 11.5 & 0.047 \\
Disagree & 76 & 46.9 & 23 & 34.8 & 53 & 55.2 & \\
Strongly disagree & 59 & 36.4 & 32 & 48.5 & 27 & 28.1 & \\
\hline At present, is nanotechnology effectively used in the field of medicine? \\
$\begin{array}{l}\text { Yes } \\
\text { Yes }\end{array}$ \\
No & 44 & 27.2 & 17 & 25.8 & 27 & 28.1 & \multirow{2}{*}{0.739} \\
\hline According to your knowledge, does nano-based treatment cause any long-term side effect? & \\
\hline Yes & 53 & 32.7 & 18 & 27.3 & 35 & 36.5 & \multirow{2}{*}{0.221} \\
No & 109 & 67.3 & 48 & 68.8 & 61 & 63.5 & \\
\hline
\end{tabular}


indicate that nanomedicine risks is not properly explained when a nanomedical subject is discussed.

\section{Nanotechnology and nanomedicine application}

Table 3 demonstrates all the students' perception about the nanomedicine application in the public and if they expect a long-term side effects when using nano-based treatment, thus to elicit the perceived knowledge of the nano-based treatment. The medical students of King Saud university, disagree $(n=76,46.9 \%)$ to strongly disagree $(n=59,36.4 \%)$ that public has awareness of the nanotechnology used in medicine. Interestingly, about $n=118,72.8 \%$ of the students think that nanotechnology is not effectively used in the medical field. When asked

Questionnaire - Nanomedicine perception among medical students in Saudi Arabia (3 minutes)

\begin{tabular}{|c|c|}
\hline (1) & $\begin{array}{l}\text { What is the year of study? (Please, enter the year you have COMPLETED) } \\
\text { (1st, 2nd, 3rd, 4th, 5th) }\end{array}$ \\
\hline (2) & $\begin{array}{l}\text { What is your gender? } \\
\text { (Male and female) }\end{array}$ \\
\hline (3) & $\begin{array}{l}\text { What is the size of the nanoparticle? } \\
\left(10^{-2}, 10^{-6}, 10^{-9} \text {, and } 10^{-12} \text { meters }\right)\end{array}$ \\
\hline (4) & $\begin{array}{l}\text { Do you know what nanomedicine is? (if you answered by No, skip to the 8th } \\
\text { question) } \\
\text { (Yes and no) }\end{array}$ \\
\hline (5) & $\begin{array}{l}\text { Where did you hear about nanomedicine? } \\
\text { (School, university, internet, newspaper, magazine, journal, television, movie, } \\
\text { books, friend, and others) }\end{array}$ \\
\hline (6) & $\begin{array}{l}\text { Do you know what nanomedicine does in respect to ethics? } \\
\text { (There is no problem with ethical issues in future, risk management needs to } \\
\text { be assessed in clinical studies, educating members in the society minimizes the } \\
\text { backlash, and it affects the public health and environment domain) }\end{array}$ \\
\hline (7) & $\begin{array}{l}\text { Do you know about risk benefit in nanomedicine? } \\
\text { (A little, some, and a lot) }\end{array}$ \\
\hline (8) & $\begin{array}{l}\text { Do you think public has awareness about application of nanotechnology used in } \\
\text { the field of medicine? } \\
\text { (Strongly agree, agree, undecided, disagree, and strongly disagree) }\end{array}$ \\
\hline (9) & $\begin{array}{l}\text { At present, is nanomedicine effectively used in the field of medicine? } \\
\text { (Yes and no) }\end{array}$ \\
\hline (10) & $\begin{array}{l}\text { According to your knowledge does nano based treatment cause any long-term } \\
\text { side effect? } \\
\text { (Yes and no) }\end{array}$ \\
\hline (11) & $\begin{array}{l}\text { What could go wrong during a nanomedical procedure? } \\
\text { (write your answer) }\end{array}$ \\
\hline
\end{tabular}


about nano-based treatment, the medical students $(n=109,67.3 \%)$ do not think that there is a long-term side effects.

\section{Nanomedical procedure perception}

This was an open question, we want to know how students' perceived nanotechnology and its usage during a hypothetical nanomedical procedure. Most of the students, answered the question as they don't know or they have no idea. Those who explained their ideas to the question, their answers were about, mistargeting or failure to deliver the medicine to affected the organ, immune reactions, toxicity, carcinogenicity, infection and malpractice.

\section{Discussion}

Nanomedicine is an emerging subject in nanotechnology science field, school students and undergraduate students should be curious about this future promising technology. Thus students are expected to be aware of basic nanotechnology science, at least to identify the nanoscale size. Unfortunately, only $63 \%$ of the King Saud's medical students identify the correct nanoscale size, as compared to a similar study done at university of Rajarata, in Sri Lank [4], in a smaller sample size of 80 medical undergraduate students, $86 \%$ of the students identified the correct answer. However, the percentage of the students who identified themselves as they know nanomedicine, is close to our study $40.7 \%$. In addition, the sources of nanomedicine information is also similar to the previous study, university, is the most cited source of information. This is hard to explain as nanotechnology is not taught in the college's curriculum of King Saud University, but this is probably from the advertisements of the nanotechnology institute in our university (King Abdullah Nanotechnology Institute).

Regarding the risk benefits of nanomedicine, interestingly $81.6 \%$ of the students had little knowledge, which is similar to the study done in Sri Lanka. Moreover, a study done among undergraduate students (including medical students) at the University of Nottingham, United Kingdom, revealed that most of the respondents were less excited and bothered about the advantages of nanotechnology. However, male participants have a positive attitude regarding its risks-benefits in treatment, than female participants [5]. Additionally, a study done on public, in the United States, participants expected the benefits to be more than the risks [6].

In terms of ethical issues in nanomedicne, $41 \%$ of our medical students, were more concerned about risk assessment in clinical studies. A semi-structured interviews with 22 nanomedicine practitioners was done by Silva Costa et al. to assess the scientists' attitude and knowledge regarding ethical issues. They found that there is uncertainty regarding the alleged novelty of nanomedicne in relation to the ethical issues and risks in their work. Most of the participants concerned more about what they experience with their co-workers regarding scientific field [7]. Additionally, a study was done in India to assess a 58 practitioner's perception regarding nanotechnology ethics using interviews, $95 \%$ of them recognized ethical issues in the field [8].

Majority of the students disagreed that public has awareness of the nanotechnology used in medicine, due to inadequate studies in regard to the issue, we can not relate this fact to their perception of the public. Furthermore, $72.8 \%$ of the students think that nanotechnology is not effectively used in the medical field, and this indicate that the students probably are not aware of the nanomedical advancements recently. Our last question in the survey was an open question, we want to know how students' perceived nanotechnology and its usage during a hypo- 
thetical nanomedical procedure. Most of the students, answered the question as they don't know or they have no idea. Who explained their ideas to the question, their answers mainly about the nanoparticles toxicity.

Internationally, nanotechnology perception among public, showed that there is a confidence toward nanomedicine technology applications in the health field. They worry more about the environmental and societal risks rather than the health issues. However, people with high education, cared more about the health issues [9]. In Singapore, public were asked about the knowledge of nanotechnology, almost $80 \%$ of the respondents, have some understanding about nanotechnology [10].

Regionally, in Iran a study revealed that $79.8 \%$ of the public heard little or nothing about nanotechnology and the level of knowledge were low among the rest [11]. In the other hand, in Turkey, a study investigates middle school student's awareness, showed that $73.9 \%$ were aware about nanotechnology [12].

In Saudi Arabia, nanotechnology is a promising technology in the country, the Saudi government is funding the institutes and the universities for this technology. Most of the funding is for water, biochemical and medical applications, yet most of the education is in higher educational level, a brief nanotechnology introduction is included in high school books.

Locally, regarding our research there were no research that assess the medical students' knowledge and understanding of concepts related to basic nanotechnology and its applications in nanomedicine as far as we know.

\section{Conclusion}

Medical students of King Saud University, showed that they have inadequate knowledge about nanotechnology and its applications in nanomedicine. Moreover, they believe that nanotechnology is not effectively used in the medical field, and most of them disagree that public has awareness of nanomedicine. Nanotechnology is a promising technology and Saudi's government is implementing and funding the research to invest in this technology. We think that nanomedicine education should be implemented in the curriculum of the medical colleges in Saudi Arabia.

\section{Limitations of the study}

This study was limited by the response percentage, future studies should have a larger sample size, preferably from multiple universities. Finally, we need to have a research that will assess the level of knowledge among the Saudi' public.

\section{Acknowledgements}

The authors extend their appreciation to the Deanship of Scientific Research at King Saud University for funding this work through undergraduate students' research support program project on (URSP-17-26).

\section{Conflicts of interest}

The authors declare that they have no conflict of interest.This work has not been published previously. All authors have contributed significantly, and are in agreement with the content of the manuscript. 


\section{References}

[1] Capon A, Gillespie J, Rolfe M, Smith W. (2015) Perceptions of risk from nanotechnologies and trust in stakeholders: a cross sectional study of public, academic, government and business attitudes. BMC Public Health 15(1) 1-13. [Serial on the Internet]. (2015, May), [cited December 26, 2015]; Available from: Academic Search Complete.

[2] ESF, E. S. F. Nanomedicine: An ESF-European Medical Research Councils (EMRC) Forward Look Report. Strasbourg cedex, France, (2004)

[3] Brenner S. (2013) The Clinical Nanomedicine Handbook Boca Raton: CRC Press; [Monograph on the Internet, cited December 26, 2015]. Available from: Discovery eBooks.

[4] Marikar F, Ilangakoon P, Jaliya S, Jayasena L, Kalavitigoda S, Kulathunga S, et al. (2014) Sri Lankan Medical Undergraduates Awareness of Nanotechnology and Its Risks. Education Research International [Serial on the Internet, cited December 26, 2015]; Available from: Publisher Provided Full Text Searching File.

[5] Nerlich B, Clarke D, Ulph F. (2007) Risks and benefits of nanotechnology: How young adults perceive possible advances in nanomedicine compared with conventional treatments. Health, Risk \& Society 9(2) 159-171. [Serial on the Internet, cited December 26, 2015]; Available from: Environment Complete.

[6] Michael D. C, Jane M. (2004) Public perceptions about nanotechnology: Risks, benefits and trust. Journal of Nanoparticle Research 6(4): 395. [Serial on the Internet, cited December 26, 2015]; Available from: Publisher Provided Full Text Searching File.

[7] Silva Costa H., Sethe S, Pego A., Olsson I. (2011) Scientists'a[euro][TM] perception of ethical issues in nanomedicine: a case study. Nanomedicine (4): 681. [Serial on the Internet, cited December 26, 2015]; Available from: Academic OneFile.

[8] Patra D., Haribabu E., McComas K. (2010) Perceptions of nanoethics among practitioners in a developing country: A case of India. Nanoethics (1) 67. [Serial on the Internet, cited December 26, 2015]. Available from: Academic OneFile.

[9] Bottini M., Rosato N., Gloria F., Adanti S., Corradino N., Magrini A., et al. (2011) Public optimism towards nanomedicine. International Journal of Nanomedicine (default) 3473. [Serial on the Internet, cited December 26, 2015]; Available from: Directory of Open Access Journals.

[10] George S, Kaptan G, Lee J, Frewer L. (2014) Awareness on adverse effects of nanotechnology increases negative perception among public: survey study from Singapore. Journal of Nanoparticle Research 16(12) 1-11. [Serial on the Internet, cited December 26, 2015]; Available from: Academic Search Complete.

[11] Farshchi P., Sadrnezhaad S., Nejad N., Mahmoodi M., Ibrahimi Ghavam Abadi L.. (2011) Nanotechnology in the public eye: the case of Iran, as a developing country. Journal of Nanoparticle Research 13(8) 3511-3519. [Serial on the Internet, cited December 26, 2015]; Available from: Academic Search Complete.

[12] Sahin N., Ekli E. (2013) Nanotechnology awareness, opinions and risk perceptions among middle school students. International Journal of Technology \& Design Education 23(4): 867-881. [Serial on the Internet, cited December 26, 2015]; Available from: Education Research Complete. 